\title{
Talent Management and Innovative Behavior Based on the Mediating Role of Organizational Learning
}

\author{
Iman Khaki ${ }^{1, a}$, Hamid Erfanian Khanzadeh ${ }^{2, b *}$, Azam Babaki Rad ${ }^{1, c}$ \\ ${ }^{1}$ Islamic Azad University, Mashhad Branch, Iran \\ ${ }^{2}$ Faculty Member, Islamic Azad University, Mashhad Branch, Iran \\ aiman.khaki@mshdiau.ac.ir, berfanian.hamid@gmail.com, cbabaki.rad@gmail.com
}

Keywords: Talent, Talent management, Innovation, Innovative behavior, Organizational learning

\begin{abstract}
This study aimed to investigate the relationship between talent management and the innovative behavior of employees based on the mediating role of organizational learning. This study is a descriptive study, according to the data collection and analysis methods and, it is a survey, according to the implementation. It was conducted during 2015 to 2016 in Mashhad, Iran. Participants were 147 staffs employed in the information technology organization of Mashhad municipality. Data were collected using three valid and reliable questionnaires. Data were analyzed using SPSS software version 19. According to the main hypothesis of the study, there is a significant relationship between talent management and the innovative behavior of employees, and organizational learning mediates the relationship between talent management and the innovative behavior of employees. Also, according to the minor hypothesis, there is a significant relationship between the components of talent management and innovative behavior and the components of organizational learning can mediate the relationship between talent management and innovative behavior. Organizational learning capability has a significant relationship with innovation and innovative behavior and the organizational learning is a way in which educational and training opportunities for employees can be linked to innovative goals.
\end{abstract}

\section{Introduction}

The recent years' ever-increasing intensity of competition in world markets, speed of globalization and quick development of technology has led innovation to be taken into account as an inevitable necessity for any firm [1].

Organizational innovation refers to the creation or adoption of an idea or behavior hence successful implementation of them within the organization [2]. The goal of innovation is to create business value by developing worthwhile ideas into a customer-centric marketable reality [3].Innovation, in addition to developing firm's capabilities enables it to correspond with environmental changes, and thus is necessary for an organization to have a long-lasting life [4- 6]. Human Resources practices have been found to play an important role in stimulating organizational innovation by enhancing the creativity of individual employees. Often innovation is seen as the result of collaboration and team work. However, innovation is largely in the hands of individuals: individuals play a vital role in all innovations because they are the holders and processors of ideas [7].

Whereas humans are the foundations of organizational transformations, talented human resource maintenance should be paid to reach the acceptable organizational level of development. The talent management is a process that traverses direction for evolution from its emersion. Talent management includes strategy and thinking based on attracting resources, selecting, training, developing, marinating, promoting and transferring workers within the organization [8].

One of the components of talent management is learning and training management. Organizational learning is a dynamic process of creation, acquisition and integration of knowledge aimed at the development of resources and capabilities leading to better organizational performance [9]. On the other hand, based on existing knowledge, there is an association between 
organizational learning and innovation that guarantees organizational growth and the future survival of organization [10].

Organizational learning and knowledge management directly influenced organizational innovation; whereas organizational learning and organizational innovation directly influenced organizational performance among manufacturing firms [11]. Zollo and Winter (2002) defined organizational learning as a collective capability based on experiential and cognitive processes and involving knowledge acquisition [12]. Templeton et al. defined organizational learning as the set of actions (knowledge acquisition, information distribution, information interpretation, and organizational memory) within the organization that intentionally and unintentionally influence positive organizational change [13].

Organizational learning can enhance the power of innovation and maintains a competitive advantage against other competitors [14]. In fact, an information-rich environment is a facilitating factor of creativity and innovation. In addition, organizations can be creative and innovative if they provide conditions for the acquisition, distribution and interpretation of knowledge and maintain and strengthen these conditions [15].The findings of the Ma'atoofi and Tajeddini's study showed that the high level of open-mindedness in small firms leads to their having more innovation [6].

Hartman et al (2010) in a study aimed to assess talent management of western companies in China found that these companies apply the talent management process through a little change based on Chinese culture [16]. Another study by Hongming, Chngyong \& Chunhui (2007) revealed that total quality management had a significant positive effect on organizational learning and as a result on the improvement of organization's innovation [17]. In the study of Chang et al (2006) on 262 teachers, it was shown that organizational learning significantly influences employees' innovation and product innovation performance [18]. Other studies have also indicated that innovation and organizational learning have a positive impact on performance improvement. Liao and $\mathrm{Wu}(2010)$ demonstrated a mediating role between knowledge and innovation [19].

Although many studies have, in the past, been examining the effect of innovation on commercial performance of firms, relatively few of these studies have been directed to recognize the dimensions and factors stimulating innovation, especially in the developing countries [6]. The present study aimed to evaluate the relationship between talent management and the innovative behavior of employees based on the mediating role of organizational learning.

\section{Theoretical Background}

\subsection{Talent Management}

Talent has been accounted as a relative level of a person's development. C.I.P.D. Institute considers the talent as a complex combination of skills, knowledge, cognitive abilities and high potentiality. Talent is the result of people's movement in the organization, how they enter the organization, how they develop their skills and how they move up or outside the organization [20]. Talent management has been defined as a system to identify, employ, nurture, improve and maintain the talented people for the aim of optimizing the organization's capacity to realize the business results [21] by using regulated guidelines, resources, policies and processes [22].

Olsen states that the traditional process of employment and recruitment needs to become an institution trying to attract and retain wide range of human talents. Proponents of this view attempt to replace talent management with the traditional terms of human resource [23].

\subsection{Components of Talent Management}

Selection and recruitment: This step is to accept or reject the demands of clients and job applicants in order to choose the most qualified, appropriate and talented of them.

Learning and training management: Each organization implements different strategies for learning depending on their circumstances, and it is well established in today's organizations because of the need for learning.

Performance management: It is a necessary lever in changing and used to increase the team and personal achievements. 
Compensatory system: Its main concern is to bring about the conditions in which payments are for increasing motivation of employees.

Pay for performance: A suitable approach for payments to the employees is that the foundation of payment depends on their performance with a special emphasis on the organization's output and income.

Succession planning: Today's perspective of organizations is, paying attention to the inside of the organization and succession planning strategy. The most successful organizations are those invested long-term in the employees [24] (Figure 1).

\subsection{Innovative Behavior}

Innovation in terms of management and organization is a process that results in creating something new. Innovation has as long history as human beings' life span because the human beings almost always want to find new ways to do their works.

Kenter believes that innovation includes the formation, adoption and implementation of new ideas in the processes, products and services [25].

Amabill (1998) defines the organization's innovation as successfully utilizing and implementing creative ideas within an organization [26].

\subsection{Organizational Learning}

Organizational learning is the process of collective learning for the members of an organization [27].

In American dictionary, learning has been defined as "gaining knowledge, understanding or mastering through experience or study" [28].

Organizational learning can be accounted as a dynamic process of creating, acquiring and collecting knowledge in order to develop resources and capacities for achieving better performance of the organization [9].

According to Neefe (2001) (Figure 1), the dimensions of organizational learning are shared vision, organizational culture, team learning, sharing knowledge, systems thinking, participative leadership, and developing the personnel competences [29].

2.4.1. Shared Vision: It is the result of collective learning that is created at the strategic level of organization and is regarded a criterion for learning at the operational level [30].

2.4.2. Organizational Culture: According to Needle (2004), organizational culture represents the collective values, beliefs and principles of organizational members and is a product of such factors as history, product, market, technology, strategy, type of employees, management style, and national culture; culture includes the organization's vision, values, norms, systems, symbols, language, assumptions, beliefs, and habits [31].

2.4.3. Team Learning: The collective learning is the process throughout which the capacity of group has been developed and synchronized in such a way that the results are something that many people have really had it [32].

2.4.4. Sharing Knowledge: The exchange of knowledge between and among individuals, and within and among teams, organizational units, and organizations. This exchange may be focused or unfocused, but it usually does not have a clear a priori objective [33].

2.4.5. Systems Thinking: Systems thinking is a set of synergistic analytic skills used to improve the capability of identifying and understanding systems, predicting their behaviors, and devising modifications to them in order to produce desired effects. These skills work together as a system [34].

2.4.6. Participative Leadership: Participative leadership defined as joint decision making or at least shared influence in decision making by a superior and his or her employees. It offers a variety of potential benefits including the increase of decisions quality, contribution in the quality of teachers' work lives, and the increase of teachers' motivation and satisfaction [35].

2.4.7. Developing Personnel Competency: In the literature of human resources competency is a set of measurable and observable knowledge, skills and behaviors that are necessary for success of a career or a position [36]. 


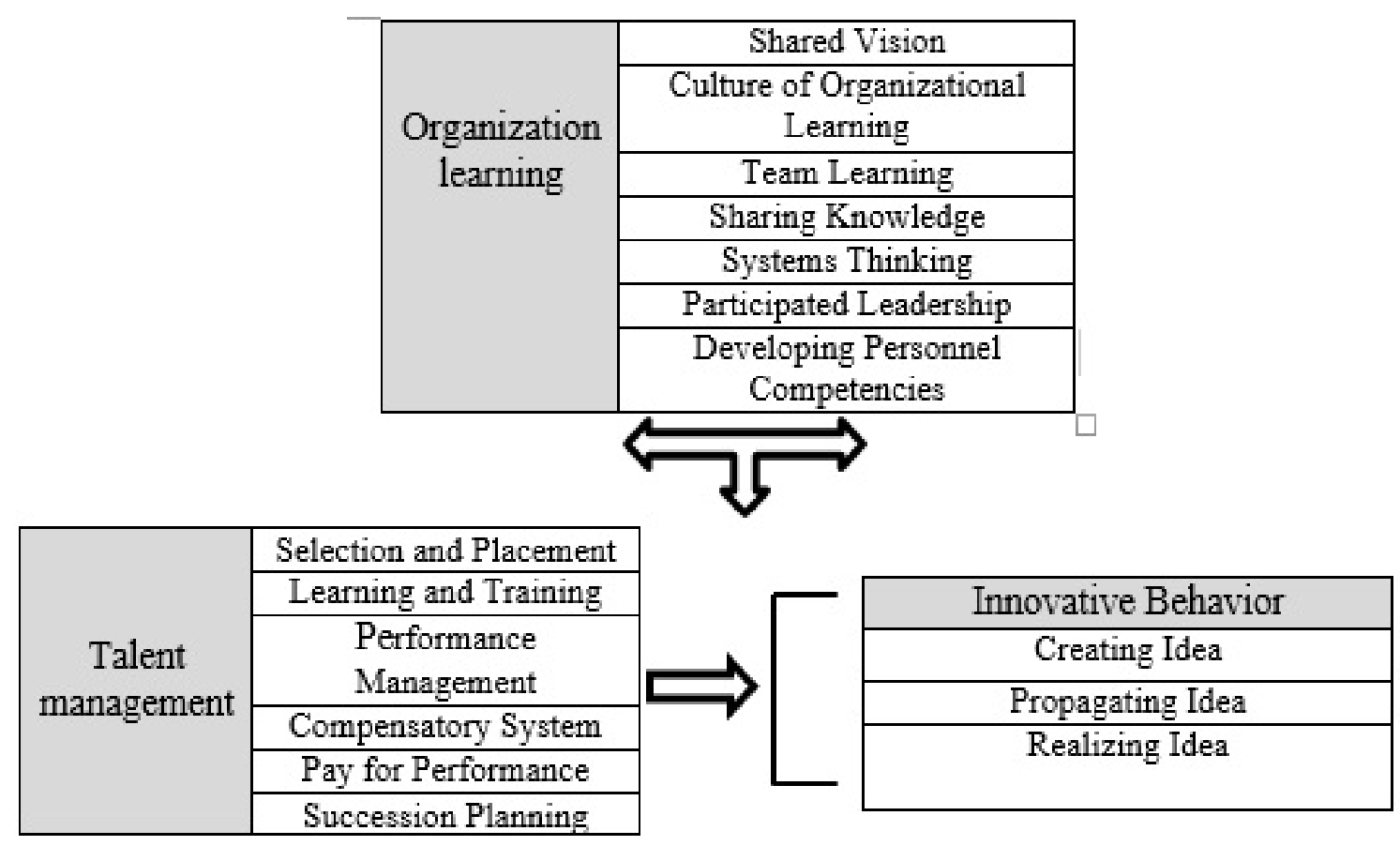

Figure 1. Conceptual Model of the study.

In this figure, the components of talent management lead to some significant changes within the organization including innovative behaviour. Organizational learning components including shred vision, culture of organizational learning, team learning, sharing knowledge, systems thinking, participated leadership, and developing personnel competencies, mediates the relationship between talent management and innovative behavior [Neefe, 2001].

\section{Research Hypotheses}

\subsection{Major Hypotheses}

- There is a significant relationship between talent management and innovative behavior.

- Organizational Learning mediates the relationship between talent management and innovative behavior.

\subsection{Minor Hypotheses}

- There is a significant relationship between the components of talent management (selection and placement, learning and training, performance management, compensatory system, pay for performance and succession planning) and innovative behavior.

- The components of organizational learning (shared vision, organizational culture, team learning, sharing knowledge, systems thinking, participative leadership, developing competencies) mediate the relationship between talent management and innovative behavior.

\section{Methodology}

This study is a descriptive, non-experimental study, according to the data collection and analysis methods and, it is a survey, according to the implementation, which was conducted during 2015 to 2016 in Mashhad, Iran.

\subsection{Data collection tool}

The main data collection instrument in this study was a three section questionnaire. The first section of the questionnaire was a brief description of how to complete the questionnaire, the second section included 3 questions about demographic information such as gender, the level of education and work experience in the organization, and the third section contained 62 questions related to the research variables. This section was researcher-made and a combination of three questionnaires: 
1. The assessment of the organization's talent management system including the components of "selection and placement, performance management, learning and training, succession planning, pay for performance, compensatory system" [37]. This questionnaire has been set in 22 items based on a 5-point Likert scale (strongly agree, agree, somewhat, disagree, strongly disagree).

2. The modified questionnaire on organizational learning has been designed in 7 dimensions (shared vision, organizational culture, team learning, strategy, participative leadership, personal mastery, and organizational structure) based on the Neefe's 7-point scale but on 22 items and based on a 5-point Likert scale (strongly agree, agree, somewhat, disagree, strongly disagree) [29].

3. Employee innovative behavior including the components of "idea generation, idea promotion, idea realization" on 12 items based on a 5-point Likert scale (always, often, sometimes, seldom, never) [38].

All these questionnaires have acceptable reliability and validity. The researcher-made questionnaire (obtained from the mentioned questionnaires), were organized in three domains including talent management, organizational learning, and employees' innovative behavior. Content validity of the questionnaire was confirmed by a number of experts and then its reliability was determined using Cronbach's alpha. The Cronbach's alpha for each domain was 0.93, 0.84 and 0.79 respectively.

\subsection{Statistical population and sampling method}

The research population consisted of all the staffs employed (147 people) in the information technology organization of Mashhad municipality. Cochrane's formula for limited population was used to determine the required sample size. Minimum required sample size was 108 people. To further ensure that a sufficient number of returned questionnaires will be returned, 120 questionnaires were distributed and of these, 113 completed questionnaires were returned. Finally, 108 questionnaires were analyzed.

It should be noted that in the present study, sampling method was simple random sampling because the population was homogeneous (only the employees of the information technology organization of Mashhad municipality) and also normal data needed to analyze the data.

\subsection{Data analysis}

Data were analyzed using descriptive and inferential statistics on SPSS software version 19. Given that the main objective of this research was to evaluate the characteristics of the organization, the correlation coefficient test was used to assess this association, and Friedman test was applied to prioritize the relationship between variables. Also, the distribution of data was determined using Kolmogorov-Smirnov test.

\section{Results}

$52 \%$ of the responders were men and $48 \%$ were women. Among the employees in Mashhad Municipality, $68 \%$ of the responders were bachelor, $23 \%$ were master, $5 \%$ were associated, $3 \%$ were $\mathrm{PhD}$ and $1 \%$ was high school graduates. According to years of service, $51 \%$ were under 5 years, $21 \%$ were $5-10$ years, $19 \%$ were $10-15$ years, $6 \%$ were $15-20$ years and $3 \%$ were 20 -up years.

After the demographic characteristics of research subjects were determined, using the research variables, the hypotheses were tested and inferences were drawn based on them. At the following, the results of analysis of assumptions will be presented:

5.1. Major hypothesis: There is a significant relationship between talent management and innovative behavior of employees. 
Table 1. Results of Pearson Correlation Coefficient of Talent Management and Innovative Behavior.

\begin{tabular}{|c|c|c|c|}
\hline Variables & Observation No. & Pearson Correlation Coefficient & P-value \\
\hline $\begin{array}{c}\text { Talent Management and } \\
\text { Innovative Behavior }\end{array}$ & 108 & 0.565 & 0.000 \\
\hline
\end{tabular}

In Table 1, the value of Pearson correlation coefficient between talent management and innovative behavior is 0.565 . Thus, $\mathrm{H}_{0}$ is strongly rejected and it can be concluded that at the $95 \%$ confidence level, "there is a significant relationship between talent management and innovative behavior of employees".

5.2. Major hypothesis: Organizational Learning mediates the relationship between talent management and innovative behavior.

Table 2. Hierarchical regression for major hypothesis 2.

\begin{tabular}{|c|c|c|c|c|c|c|c|}
\hline $\mathbf{R}^{2}$ & P-Value & $\mathbf{F}$ & P-value & $\mathbf{T}$ & $\begin{array}{l}\text { Standard } \\
\text { Deviation } \\
\end{array}$ & $\begin{array}{c}\text { Standard } \\
\text { Coefficients }\end{array}$ & \\
\hline \multirow[b]{2}{*}{0.313} & \multirow[b]{2}{*}{0.000} & \multirow[b]{2}{*}{49.810} & 1.000 & & 0.057 & - & Constant \\
\hline & & & 0.000 & 7.058 & 0.084 & 0.565 & Talent Management \\
\hline \multirow{3}{*}{0.323} & \multirow{3}{*}{0.000} & \multirow{3}{*}{26.545} & 1.000 & 0.000 & 0.057 & - & Constant \\
\hline & & & 0.014 & 2.491 & 0.155 & 0.367 & Talent Management \\
\hline & & & 0.113 & 1.597 & 0.163 & 0.235 & $\begin{array}{l}\text { Organizational } \\
\text { Learning }\end{array}$ \\
\hline \multirow{4}{*}{0.396} & \multirow{4}{*}{0.000} & \multirow{4}{*}{24.367} & 0.029 & -2.216 & 0.067 & - & Constant \\
\hline & & & 0.121 & 1.565 & 0.152 & 0.226 & Talent Management \\
\hline & & & 0.097 & 1.674 & 0.154 & 0.233 & $\begin{array}{l}\text { Organizational } \\
\text { Learning }\end{array}$ \\
\hline & & & 0.000 & 3.691 & 0.110 & 0.312 & $\begin{array}{l}\text { Talent Management* } \\
\text { Organizational } \\
\text { Learning }\end{array}$ \\
\hline
\end{tabular}

In Table 3 shows that the first and third equations are different from each other, that is, $b_{1} \neq 0$ is significant in the first regression equation ( $\mathrm{P}$-value $=0.000<0.05) ; b_{3} \neq 0$ is significant in the third regression equation $(\mathrm{P}-\mathrm{value}=0.000<0.05)$. Therefore, it can be generally stated that organizational learning has a mediating effect. Thus, the result of second major hypothesis is as following with the $95 \%$ confidence interval: organizational Learning mediates the relationship between talent management and innovative behavior of employees.

Minor hypothesis: There is a significant relationship between the components of talent management (selection and placement, learning and training, performance management, compensatory system, pay for performance and succession planning) and innovative behavior.

Table 3. Results of Pearson Correlation Coefficient of Talent Management and Innovative Behavior of Employees.

\begin{tabular}{cccc}
\hline P-value & $\begin{array}{c}\text { Pearson Correlation } \\
\text { Coefficient }\end{array}$ & Observation No. & $\begin{array}{c}\text { Components of Talent } \\
\text { Management }\end{array}$ \\
\hline 0.000 & 0.467 & 108 & selecting and replacing innovative \\
& & 108 & behavior \\
0.000 & 0.357 & 108 & learning and training \\
0.000 & 0.532 & 108 & performance management \\
0.000 & 0.534 & 108 & compensatory system \\
0.000 & 0.503 & 108 & pay for performance \\
0.000 & 0.503 & & succession planning \\
\hline
\end{tabular}


According to Table 3, the values of Pearson correlation coefficients between talent management components (selecting and replacing, learning and training, performance management, compensatory system, pay for performance, succession planning) and innovative behavior respectively are $0.467,0357,0.532,0.534,0.503$, and 0.503 . Totally, this result indicates a direct linear relationship between these two variables.

The probability value of this relationship is smaller than the level of test error $(a=0.05$; $\mathrm{P}$-value $=0.000<a=0.05)$. Thus, $\mathrm{H}_{0}$ is strongly rejected and it can be concluded that with $95 \%$ confidence level, "there is a significant relationship between the components of talent management (selection and placement, learning and training, performance management, compensatory system, pay for performance and succession planning) and innovative behavior".

5.4. Minor hypothesis: The components of organizational learning (shared vision, organizational culture, team learning, sharing knowledge, systems thinking, participative leadership, developing competencies) mediate the relationship between talent management and innovative behavior.

According to Table 4, reveals that the components of organizational learning (shared vision, organizational culture, team learning, sharing knowledge, system thinking, participative leadership, developing competencies) have a mediating effect. Thus, the result of second minor hypothesis is as following with 95\% confidence level: "the components of talent management (selection and placement, learning and training, performance management, compensatory system, pay for performance and succession planning) mediate the relationship between talent management and the innovative behavior of employees".

Table 4. Hierarchical Regression for Major Hypothesis 2.

\begin{tabular}{|c|c|c|c|c|c|c|c|}
\hline $\mathbf{R}^{2}$ & P-Value & $\mathbf{F}$ & P-value & $\mathbf{T}$ & $\begin{array}{l}\text { Standard } \\
\text { Deviation }\end{array}$ & $\begin{array}{c}\text { Standard } \\
\text { Coefficients }\end{array}$ & \\
\hline \multirow{4}{*}{0.420} & \multirow{4}{*}{0.000} & \multirow{4}{*}{26.872} & 0.018 & -2.405 & 0.064 & - & Constant \\
\hline & & & 0.000 & 5.031 & 0.128 & 0.610 & talent management \\
\hline & & & 0.024 & -2.289 & 0.111 & -0.269 & shared vision \\
\hline & & & 0.000 & 4.216 & 0.091 & 0.352 & $\begin{array}{l}\text { talent management * } \\
\text { shared vision }\end{array}$ \\
\hline \multirow{4}{*}{0.381} & \multirow{4}{*}{0.000} & \multirow{4}{*}{21.351} & 0.181 & -1.346 & 0.064 & - & Constant \\
\hline & & & 0.004 & 2.921 & 0.118 & 0.328 & talent management \\
\hline & & & 0.052 & 1.962 & 0.107 & 0.205 & organizational culture \\
\hline & & & 0.009 & 2.655 & 0.101 & 0.228 & $\begin{array}{l}\text { talent management } * \\
\text { organizational culture }\end{array}$ \\
\hline \multirow{4}{*}{0.363} & \multirow{4}{*}{0.000} & \multirow{4}{*}{25.351} & 0.027 & -2.241 & 0.064 & - & Constant \\
\hline & & & 0.017 & 2.433 & 0.116 & 0.267 & talent management \\
\hline & & & 0.014 & 2.498 & 0.096 & 0.252 & team learning \\
\hline & & & 0.000 & 4.067 & 0.109 & 0.345 & talent management $*$ team learning \\
\hline \multirow{4}{*}{0.383} & \multirow{4}{*}{0.000} & \multirow{4}{*}{23.169} & 0.028 & -2.229 & 0.068 & - & \multirow{4}{*}{$\begin{array}{c}\text { Constant } \\
\text { talent management } \\
\text { participative leading } \\
\text { talent management } * \text { participative } \\
\text { leading }\end{array}$} \\
\hline & & & 0.001 & 3.320 & 0.141 & 0.443 & \\
\hline & & & 0.779 & -0.281 & 0.113 & -0.035 & \\
\hline & & & 0.000 & 3.711 & 0.096 & 0.320 & \\
\hline \multirow{4}{*}{0.425} & \multirow{4}{*}{0.000} & \multirow{4}{*}{27.318} & 0.091 & -1.704 & 0.063 & - & \multirow{4}{*}{$\begin{array}{c}\text { Constant } \\
\text { talent management } \\
\text { developing competencies } \\
\text { talent management } * \text { developing } \\
\text { competencies }\end{array}$} \\
\hline & & & 0.072 & 1.820 & 0.113 & 0.195 & \\
\hline & & & 0.000 & 4.266 & 0.099 & 0.430 & \\
\hline & & & 0.003 & 3.091 & 0.106 & 0.250 & \\
\hline \multirow{4}{*}{0.401} & \multirow{4}{*}{0.000} & \multirow{4}{*}{24.923} & 0.019 & -2.374 & 0.066 & - & \multirow{4}{*}{$\begin{array}{c}\text { Constant } \\
\text { Talent management } \\
\text { organizational structure } \\
\text { Talent management } * \\
\text { organizational structure }\end{array}$} \\
\hline & & & 0.003 & 2.992 & 0.121 & 0.342 & \\
\hline & & & 0.142 & 1.481 & 0.097 & 0.163 & \\
\hline & & & 0.000 & 4.064 & 0.097 & 0.323 & \\
\hline \multirow{4}{*}{0.399} & \multirow{4}{*}{0.000} & \multirow{4}{*}{24.720} & 0.027 & -2.240 & 0.064 & - & \multirow{4}{*}{$\begin{array}{c}\text { Constant } \\
\text { talent management } \\
\text { strategy } \\
\text { talent management } * \text { strategy }\end{array}$} \\
\hline & & & 0.001 & 3.406 & 0.116 & 0.375 & \\
\hline & & & 0.751 & 0.319 & 0.084 & 0.034 & \\
\hline & & & 0.000 & 4.062 & 0.083 & 0.349 & \\
\hline
\end{tabular}




\section{Discussion}

This research has been assessed the relationship between talent management and the innovative behavior of employees based on the mediating role of organizational learning.

Thirteen minor hypotheses have been presented. The first major hypothesis is confirmed for the relationship between talent management and the innovative behavior of employees. Results showed that the innovative behavior of employees increases as the talent management increases for the employees, in other words, if the innovative behavior of employees increases, the talent management will increase, too. This finding is in accordance with the study of Nopasand and Ashegh-Hosseini Mehrvani [39]. Talented people are those who regularly demonstrate exceptional ability and achievement either over the range of activities, and situations or within a specialized field [40]. These findings are consistent with other studies [41-43].

According to the results, the organization can employ efficacious and talented people in the various jobs by doing actions such as developing a valid brand, creating the optimum mentality in the society especially in the geniuses and talented people, utilizing an employment system and promoting inside the organization, allocating appropriate working hours, enough salary and benefits, presenting employment contracts with high security and providing welfare and entertainment facilities.

Because of the daily increasing importance of human resources as an important factor for developing the organizations in the competition era, the continuous training and improvement of the human resources seem to be very essential. Therefore, the managers have to think of empowering the employees based on recognizing the existing gaps in the organizations and suggesting the principled and logical solutions.

Often one of the misconceptions about talent management is that talent management is considered as an independent process of other human resources' processes. When we discuss about talent management, there may be this misconception that a number of special people should be necessarily selected and special services be provided to them.

However, as the experiences of the top companies in the world about the talent management have shown, talent management should be institutionalized as an ongoing system in relation with the each of processes of human resources development.

In fact, talent management belongs to all processes of human resources development and is for training and promoting all employees. However, identifying and selecting a number of people with aims such as succession planning is one of its processes.

The role of talent management is crucial in the collections that creativity and innovation are the vital factors and requirements of the organization because talent management can create, propagate and encourage the creativity and innovation potentials among people and/or their behaviors and performances can preclude this vital issue. The art of a creative manager is that $\mathrm{s} / \mathrm{he}$ uses the creativity of others and finds the creative minds. A creative manager does not limit $\mathrm{him} /$ herself to traditional and common methods, but s/he chooses a style for management that is very appropriate for the creative and innovative organization leading to an environment dominated by the soul of originality and innovation. In the creative organizations, the relations between the managers and the employees are based on sincerity, clarity and collaboration, resulting in the sense of security and peace of mind. The creative managers act more efficiently than non-creative managers in creating appropriate job opportunities, creating an organizational space for the more attempt of employees, and increasing the efficiency of the organization. They creatively try to eliminate plights and problems.

The second major hypothesis was confirmed at the 5\% significance level. So, it can be said that organizational learning has a mediating effect. In other words, the increased level of organizational learning is associated with a positive relationship between talent management and innovative behavior.

Some studies have been carried out on investigating the mediating role of organizational learning in the relationship between talent management and innovative behavior. Their results are partially similar to the results of this research [44, 17-19]. 
Organizational learning plays a very important role in achieving the goals [38], supporting the creativity, and producing new knowledge and ideas [39]. Indeed, it can be said that organizational learning is a way in which the educational and training opportunities of employees are linked to the innovative aims.

These results show that organizational learning capability has a significant relationship with innovation and innovative behavior and they emphasize the importance of learning for innovation performance.

\section{Recommendations of the Study}

According to the results, the managers can be ensured that by implementing the talent management process and creating a treasury of talent in the organization, when needed, they can have access to the quality and efficient staff in order not to face any crisis in that regard. This research emphasize that it can be hoped to improve the organization's affairs by using talent management, identifying the key positions and placing the people in these positions. But, what ultimately make talent management to be associated with optimum results for the organization are the full support of the managers and the continuation of this support. Otherwise, no success will be reached.

In addition, according to the study results, the following suggestions are presented:

- On the strategic approaches, and the operational goals and programs, the organizations should pay more attention to talent management and the accurate timing for implementing talent management.

- Another important point that should be mentioned is that, although talent management is one of the most important matters that has gained enough attention in the organizations, doing it based on the law cannot guarantee its success in the organization but as it has been emphasized in the literature, talent management needs a strong determination and full support of the employees and managers. So, the culture of talent management is suggested to be established among the employees and managers, and all organization have accepted and believed that talent management will have a deep influence on the organization's performance. To do so, the basic factors have to be taken into consideration, and at the meta-organizational level, the government and the parliament consider this as one of the important development indicators of the country more serious than before lucidly in the country's bills and laws.

- The managers in actions and in words should have a positive and operational approach in implementing talent management and provide full financial and spiritual supports in this field.

- The organizations can increase their innovations through organizational learning, paying attention to the employees' new ideas and suggestions, communicating with outside environment, and using the environmental features for learning.

-The organizations should pay a special attention to the method of learning, acquisition of information and the interpretation of information to improve the organizational learning. In addition, the organizations should pay attention to the learning and innovation in order to increase the effects of learning on the innovation capability and try to go through their related processes accurately and completely.

- The manager should provide the training courses to improve the organizational learning.

- It is important to be encouraged the behaviors that contribute to the transfer and distribution of knowledge in the organization and is the result of learning atmosphere and process for the employees.

- The training courses are suggested to become innovative as possible and have the aspect of continuous improvement in training. These schemes should be prepared with the collaboration of various sections in the organization representing the aims and plans of those sections.

- The managers have to consider the new ideas and improve the quality and production of new products using innovative technologies.

- At the government level, it is suggested that in order to evaluate the organization's performance, the state laws take into account the talent management. In other words, the 
implementation of talent management should be one of the indicators of performance measurement of a ministry. If the organizations do not follow the orders in this case, they get negative scores and consequently their annual budget will be influenced.

- The managers should pay attention to the need for maintaining the capable staff because the failure or the success of an organization depends on the talented staff.

- The organizations and managers should pay attention to talent management for promoting organizational culture.

- The managers should provide the situation in which the works are done by team, the information is fairly distributed to all the organization, the employees help to decide, the communications are open and friendly, the administrators respect the subordinates and give them rewards appropriate to their performance, and finally the sessions are properly efficient.

- There should be some activities in the organization that encourage the employees to solve problems in teamwork before referring to the administrators.

- The administrators of organizations should provide enough incentives and motivations for employees in order to make them change their traditional behaviors and thoughts, use the innovation power for seeking the new resources and accept the suggestions of others regarding the new problem solving methods

- The managers can utilize the employees' innovative ideas and comments through various methods Such as Delphi brainstorming technique. Delphi technique includes invitation to consultation and the comparison of, unnamed member's judgments about the decision or the problem.

- As the creative people, they should develop new thoughts and beliefs in the organization and in the other levels using systems thinking. Systems thinking plus creativity as a component of the system can be helpful in reaching the goals. This component helps the managers to receive the optimum meaning and can increase the quality of career in the management field.

- The managers should support and encourage the staff to learn continuously and invite them to participate in the innovative processes and projects in the municipality.

- The managers should create appropriate working conditions for the employees through it they can completely show their skills and abilities.

- Developing the talents and human resources will be the important part of organization's movement toward the creation of a learning organization. To create a learning organization, it is first necessary that an organization possesses the organizational learning capacity. To institutionalize the organizational learning, the learning and development programs is essential for the staff in the organization.

- By creating the career development plans in the organization, people will have much more job satisfaction and the organization will benefit from the advantages of learning organization. Thus, it is suggested that the organizations take into consideration the educational and personal development programs.

\section{Acknowledgements}

The authors would like to thank the participants for their sincere cooperation in this study. The authors declare that there is no conflict of interests. 


\section{References}

[1] K. Tajeddini, M. Trueman, G. Larsen, Examining the effect of market orientation on innovativeness, Marketing Management. 22(5-6) (2006) 529-551.

[2] T.M. Amabile, How to kill creativity, Harv. Bus. Rev. 6(5) (1998) 77-87.

[3] J. Lee, M. Abu Ali, Innovative product advanced service systems (I-PASS): methodology, tools, and applications for dominant, Int. J. Adv. Manuf. Technol. 52(9-12) (2010) 11611173.

[4] J.H. Collins, J. Moschler, The life cycle of innovations, Defense AR Journal. 15(1) (2008) 7585.

[5] J. Rhee, T. Park, D.H. Lee, Drivers of innovativeness and performance for innovative SMEs in South Korea: mediation of learning orientation, Technovation. 30(1) (2009) 65-75.

[6] A.R. Ma'atoofi, K. Tajeddini, The effect of entrepreneurship orientation on learning orientation and innovation: a study of small-sized business firms in Iran, International Journal of Trade, Economics and Finance. 1(3) (2010) 254-260.

[7] A.A.R. Veenendaal, Enhancing innovation at work through human resource management, Ph.D. dissertation, Twente Uni., 2015.

[8] M.F. Nosh Abadi, S.M. Khadem, A. Sadeghnia, Talent management and maintaining talented human resource: a case study in Kashan University of Medical Sciences, European Online Journal of Natural and Social Sciences. 2(3) (2013) 3446-3457.

[9] A. Kazzazi, A. Shoul, Total quality management impact on innovation performance: moderating effect of organizational learning, Motaleate Modiriyat (Behbood va Tahavol). 22 (2013) 1-17. [In Persian].

[10] J. Alegre, R. Chiva, Entrepreneurial orientation, organizational learning capability and performance in the ceramic tiles industry, Instituto Valenciano de Investigaciones Economicas, SA. (2009) 3-29. Available: http://www.ivie.es.

[11] A. Noruzy et al., Relations between transformational leadership, organizational learning, knowledge management, organizational innovation, and organizational performance: an empirical investigation of manufacturing firms, Int. J. Adv. Manuf. Technol. 64 (2013) 10731085 .

[12] M. Zollo, S.G. Winter, Deliberate learning and the evolution of dynamic capabilities, Organ Sci. 13(6) (2002) 339-351.

[13] G.F. Templeton, B.R. Lewis, C.A. Snyder, Development of a measure for the organizational learning construct, Manag. Inf. Syst. 19(2) (2002) 175-218.

[14] A. Fernandez-Mesa et al., Design management capability: It's mediating role between OLC and innovation performance in SMEs, Paper to be presented at the DRUID Academy, University of Cambridge, The Moeller Centre, 2012.

[15] W.E. Baker, J.M. Sinkula, Learning orientation and product innovation: delving into the organization's black box, Market Focus Manage. 5 (2002) 5-23.

[16] E. Hartmann, E. Feisel, H. Schober, Talent management of western MNCs in China: Balancing global integration and local responsiveness, Journal of World Business. 45(2) (2010) 169-178.

[17] X. Hongming, L. Chngyong, C. Chunhui, Relationships among market orientation, Learning orientation, organizational innovation and organizational performance, an empirical study in the Pearl River Delta region of China, Frontiers of Business Research in China. 1 (2007) 222253. 
[18] S.C. Chang et al., The study of social capital, organizational learning, innovativeness, intellectual capital, and performance, Human Resource and Adult Learning. 2 (2006) 63-71.

[19] S.H. Liao, C.C. Wu, System perspective of Knowledge management, organizational learning and organizational innovation, Expert Systems with Applications. 37 (2010) 1096-1103.

[20] S. Sayyadi, M. Mohammadi, A. Nikpoor, Talent management: A key concept in the field of human resources, Kar O Jamee. 135 (2011) 81-86. [In Persian].

[21] K. Tajeddin, M. Maali Tafti, Why Talent management, Tadbir. 191 (2008) 63-92. Available: http://www.noormags.com/view/fa/default. [In Persian].

[22] M. Guy, D. Sims, Future talent development: a practical guide to talent management and succession planning, in: N. Jazani, Saramd, Tehran, Iran, 2009.

[23] D.G. Collings, K. Mellahi, Strategic talent management: A review and research agenda, Human Resource Management Review. 19 (2009) 304-313.

[24] M.A. Mokhtari, Talent management, Ketabe Mahe Olome Ejtemaei. 139 (2011) 124-129. [In Persian].

[25] S.R. Agha-Davud, M. Hatami, B. Hakiminia, Evaluation of organizational innovation among managers. Case study: senior managers of communication organization of Isfahan, Iran, Islamic Azad University, Shushtar Branch, Quarterly Professional Journal of Social Sciences. 11 (2010) 120-170. [In Persian].

[26] T.M. Amabile, A model of creativity and innovation in organizations, Research in Organizational Behavior. 10 (1998) 123-167.

[27] G. Yukl, Leading organizational learning: Reflections on theory and research, The Leadership Quarterly. 20 (2009) 49-53.

[28] M.H. Olson, B.R. Hergenhahn, An introduction to theories of learning, $4^{\text {th }}$ edition, Taylor and Francis group, 2016.

[29] D.O. Neefe, Academic quality improvement project: comparing levels of organizational learning maturity of M.M. Crossan, H.W. Lanne, R.E. White, (1999). An organizational learning framework: from intuition to institution, Academy of Management Review. 24 (2001) 165-179.

[30] E. Molleman, H. Broekhuis, Socio-technical systems: towards an organizational learning approach, Engineering and Technology Management. 18 (2001) 271-293.

[31] D. Needle, Business in context: an introduction to business and its environment, $5^{\text {th }}$ edition, London, UK, Cengage Learning EMEA, 2004.

[32] P. Senge, The fifth discipline: The art and practice of learning organization, Double day Dell, New York, 1990.

[33] D. Paulin, K. Suneson, Knowledge transfer, knowledge sharing and knowledge barriers three blurry terms in KM, Electronic Journal of Knowledge Management. 10(1) (2012) 8191.

[34] R.D. Arnold, J.P. Wade, A definition of systems thinking: a systems approach, Procedia Computer Science. 44 (2015) 669-678.

[35] A. Somech, Directive versus participative leadership: two complementary approaches to managing school effectiveness, Educational Administration Quarterly. 41(5) (2005) 777-800.

[36] J.C. Hayton, D.J Kelley, A competency-based framework for promoting corporate entrepreneurship, Human Resource Management. 45(3) (2006) 407-427. 
[37] A.A. Ahmadi, F. Ahmadi, J. Abbasalangi, Talent management and succession planning interdisciplinary, Contemporary Research in Business. 4(1) (2012) 213-224.

[38] B.W. Amo, Employee innovation behavior, PhD dissertation, Bodo Graduate School of Business, Bodo Regional Univ., Norway, 2005.

[39] S.M. Nopasand Asil, M. Ashegh Hosseini Mehrvani, Motaleate Modiriyate Behbood va Tosee. 75 (2014) 19-38. [In Persian].

[40] P. Iles, X. Chaui, D. Preece, Talent management and HRM in multinational companies in Beijing: definitions, differences and drivers, World Business. 45 (2010) 179-189.

[41] C. Kontoghiorghes, S. Awbre, P. Feurig, Examining the relationship between learning organization characteristics and change adaptation, innovation, and organizational performance, Human Resource Development Quarterly. 2 (2003) 185-213.

[42] J. Sullivan, Talentonomics: proving the economic value of talent management, 2009. Available: https://www.eremedia.com/ere/talentonomics-proving-the-economic-value-oftalent-management/.

[43] C. Tansley et al., Talent: strategy, management, measurement, Chartred Institute of Personal \& Development, Plymouth, 2007.

[44] J. Alegre, R. Chiva, Assessing the impact of organizational learning capability on product innovation performance, Technovation. 28 (2008) 315-326.

[45] J.A. Aragon-Correa, V.J. Garcia-Morales, E. Cordon-Pozo, Leadership and organizational learning's role on innovation and performance: lessons from Spain, Industrial Marketing Management. 36 (2007) 349-359. 